\title{
Society Teproxts.
}

\section{THE NEW YORK NEUROLOGICAL SOCIETY.}

Stated Meeting, held at the New York Academy of Medecine, Tuesday evening, April 4 th, I 893 .

Dr. M. Allen Starr, President, in the chair.

Dr. G. M. Hammond, presented a case of locomotor ataxia which he has been treating with hypodermic injections of cerebrine. Six years ago, the patient, a man of 40 years, began to suffer with double vision. This, after several months of treatment, disappeared, and for a time he was quite well. Then the typical symptoms of locomotor ataxia came on. There was a complete loss of the knee jerks; he had sharp pains in his legs; the ataxic gait was well marked; there was inability to stand with the eyes closed, even when the legs were some distance apart: he had difficulty in evacuating his bladder and. bowels; his sexual power was lost; he had a sense of constriction around the waist; there were no eye symptoms. The man denies syphilis. Treatment was commenced about ten weeks ago, and consisted of a daily hypodermic injection of Cerebrine, five minims, combined with five minims of water. Dr. Hammond said he presented the case with some diffidence, on account of the method of treatment employed; no one has had less faith in these animal extracts than himself. The improvement in this case, however, has been very marked. The man's sexual functions have been perfectly restored; he has complete control over his bladder and bowels; the sharp pains have disappeared; his general health has improved; he is able to run up and down stairs and stands fairly steady with his eyes closed. The knee jerks, however, have not returned. No other treatment was employed. The improvement was gradual and steady, and began about a week after the first injection. The cerebrine employed was that prepared by Dr. William A. Hammond. 
Dr. Joseph CoLlins said that he has employed subcutaneous injections of Cerebrine, as prepared by Dr. Paul Gibier, in a few cases of locomotor ataxia; the improvement in those cases was about equal to that in Dr. Hammond's patient. It is not uncommon, he said, to see the virile powers return in these patients; this has occurred after applying blisters to the spine. A case has also been reported in which the shooting pains disappeared with the injections of phosphate of soda.

Dr. HAMMOND also presented a boy, with the following history: Two years ago, while rowing a boat, the oar in the left hand slipped from his grasp, and his fingers lost their power. In about five minutes he was unable to use four fingers, but not the thumb; and from that time on the paralysis has progressed, first spreading to the other muscles of the hand and gradually to those of the arm. Fibrillary twitchings were very marked. There is now hemiatrophy of the tongue and paralysis of one of the ocular muscles, with double vision. The boy has lost the power of whistling and of speaking certain words. There is incoördination on standing with the eyes closed, and loss of knee-jerks on both sides; no other ataxic symptoms. No sharp pains; no bladder nor bowel symptoms; no anæsthesia nor parasthesia; The expression of the boy's face is rather characteristic of hereditary syphilis; the boy's father is now under treatment for that disease. There is no history of acquired syphilis. There are no objective symptoms. Dr. Hammond presented the case as one of progressive muscular atrophy, probably of specific origin.

\section{SYPHILIS OF THE SPINAL CORD.}

Dr. B. SACHS read a paper on this subject. He first reviewed the recent work of Erb on this subject. Erb has sought to establish a "type " of spinal cord disease, which he proposes to label "syphilitic spinal paralysis." This special type is to be recognized by the following characteristics: I. The ustial symptoms of spastic paraplegia, with its peculiar gait, carriage and movements. 2. The reflexes are very much exaggerated. 3. The muscular contractures are slight as compared with the exaggeration of the reflexes. 4. Involvement of the bladder. 5. A slight but distinct disturbance of sensation. 6. Gradual onset of the disease. 7. A decided tendency to improvement. 
Dr. Sachs said that while he did not mean to dispute the existence and the propriety of establishing Erb's type of spinal disease, he believes there are other and broader points of diagnosis which should not be disregarded. To illustrate these points, he gave the history of four cases of undoubted syphilitic disease of the spinal cord. In these cases, the following were the salient features which led to the diagnosis: In three of them there was spastic paraplegia of the most pronounced type. In these the reflexes were excessively exaggerated. In two the muscular contractures were slight; in one of them they were extreme. In one there was permanent involvement of the bladder; in the others there was no such involvement. In all but one of them sensation was disturbed. In two the onset was gradual; in the others it was quite sudden. All of them have shown a decided tendency to improvement. In one instance there was a distinct atrophic paralysis, with all the symptoms that pointed to a widespread affection of the gray matter of the cord. In one case, in which the diagnosis of syphilitic disease was more evident than in any of the others, the contractures were extreme, the bladder has remained involved, up to the present time, and bed-sores formed, as in most typical cases of acute transverse myelitis.

Dr. Sachs said that the following points have impressed themselves on his mind as the more characteristic of spinal cord syphilis. I. The usual distribution of the disease over the greater portion of the cord, involving, in some cases, the cervical, lower dorsal and lumbar enlargements. 2. The relatively slight intensity of the morbid process as compared with the extensive area involved, as evidenced by the preservation of some of the functions of the cord with complete loss of others. 3. A rapid dwindling of some of the symptoms and a very chronic persistence of others. 4. The very frequent history of other symptoms pointing to specific disease in the same or in other parts of the central neryous system.

In specific spinal cord disease there is not, as in cases of acute myelitis, a morbid process which is rapidly destructive and which quickly advances through the entire cross-section of the cord, involving all the symptoms due to loss of function of the various spinal systems. If the syphilitic disease be the result of a specific endarteritis of the vessels of the cord, we know that some, and by no means all, of these vessels are affected, and that the disease advances slowly from one 
group to another. If there be diffuse specific infiltration, it also invades very slowly one part after the other. It has a remarkable tendency, too, to increase for a time and then to recede, whether as a result of treatment or not, and then possibly to increase with renewed force. If the infiltration start from the meninges, it invades most frequently the lateral columns first, often at symmetrical points, and advances very slowly from white to gray matter. The intensity of the process is spent upon the lateral columns; hence the frequency of the spastic symptoms. It may invade the gray matter, giving rise to sensory symptoms, sometimes to atrophic symptoms.

Dr. C. L. DANA said that in one case of spinal cord syphilis coming under his observation, the patient died of an intercurrent disease and an autopsy was obtained. The type of symptoms in that case resembled so closely what Gowers described as ataxic paraplegia that that was the clinical term applied to it. The autopsy showed a transverse myelitis, of specific origin, in the dorsal region, and the appearance of the lesion was much like that described by Dr. Sachs-starting from the meninges and gradually invading the substance of the cord. Dr. Dana said he has almost come to the conclusion that whenever we get a transverse myelitis, which is not manifestly due to hæmorrhage, tumor, injury, etc., and which does not develop suddenly, but comes on gradually and irregularly, we have presumptive evidence of its specific origin.

Dr. E. C. SEgurn said that Dr. Sachs' description of syphilitic disease of the cord coincided very closely with his own experience. The irregularity or lack of completeness of the symptom group is a very characteristic feature in these cases. Dr. Seguin also referred to another class of cases, namely, those in which the symptoms are those of pressure upon the spinal cord, as we get in paraplegia dolorosa, or the myelitis of compression. He gave the histories of two such cases coming under his observation.

Dr. L. C. GRAY said he has long regarded with suspicion any case of paralysis of the upper or lower extremities, with marked contractures, with or without inciease of the tendon reflexes. This is particularly true in cases where the symptoms are unequal or asymmetrical. The poison of syphilis, however, is so diffused that it is unsafe to assume that its effect is spent entirely upon any particular set of fibres in the spinal cord, and it is difficult 
to lay down a certain class of symptoms which should be present in these cases.

Dr. RobERT S. NEwTon gave the history of a patient who developed the symptoms of a transverse myelitis while under active treatment for syphilis; at the time of the attack, the treatment had been persisted in for over a year.

The discussion was then closed by Dr. Sachs.

\section{THE PRESENT STATUS OF CRANIECTOMY.}

Dr. L. C. GRAY opened the discussion on this subject. He stated that about three years ago Lannalongue proposed the operation of craniectomy for the relief of mental defects in children. The causes of such mental defects are, in the main, the following: Porencephalitis ; meningitis and meningo-encephalitis ; hæmorrhage, either diffused or localized; trauma; hydrocephalus; myxœdema; possible premature ossification of the skull, mainly in the region of the sutures and fontanelles. The latter cause has been brought into prominence lately by Lannalongue's operation, although the idea did not originate with him; it was advocated, as far back as $185 \mathrm{I}$, by Virchow, in his memoir upon cretinism, and it has been under discussion since in various other writings. It is impossible to obtain, in this country at least, a sufficient number of skulls of idiots whose histories have been carefully recorded, to pass upon any question of this kind by the examination of skulls. Tacquet has examined 29 skulls of idiots, and believes as a result of this investigation that obliteration of the sutures of the cranium is not more premature in idiots than in healthy individuals, so that the arrest of cerebral development was in none of his cases the result of an arrest of development of the skull. Dr. Gray said he is entirely at a loss to understand how an examination of the skulls of these idiots could throw any light upon the question as to whether primary ossification of the sutures and fontanelles arrested the development of the cerebrum. Tacquet's conclusions, he thought, are not supported by his cases.

Of all the causes of idiocy above mentioned, only the premature ossification of the sutures and fontanelles, recent traumatic injuries and hæemorrhages, Dr. Gray said, can possibly be benefited by craniectomy, for porencephalitis, meningitis, meningo-encephalitis and myxœdema are lesions that the surgeon's knife cannot 
in any way affect. A correct diagnosis in these cases is of the utmost importance. If, in any case of idiocy, we can obtain a reliable history from some one who has been with the child since birth, best of all its own mother, and we can positively exclude trauma, meningitis, hæmorrhage and myxœedema, we shall then only have to deal with socalled tuberous hypertrophy, porencephalus and premature ossification of the sutures and fontanelles. Tuberous hypertrophy is so rare as to be practically of no account. Porencephalus occurs generally in fotal or early infantile life, and will in a vast majority of cases cause some paralysis of motion or sensation. Porencephalus, meningitis, hæmorrhage, trauma and tuberous hypertrophy are very likely to cause some organic destruction of the cerebrum or cerebellum, and this must manifest itself by mutism, blindness, motor paralysis, localized convulsions or contracture of a single limb or of both an upper and lower limb on the same side. If, in an idiot child, we can exclude these symptoms, it seems quite reasonable to make a diagnosis of a premature ossification of the sutures and fontanelles as causative of the mental condition. The speaker said he was quite willing to believe that the pressure of a non-expanding skull upon a cerebrum, expansile with developing tendencies, is sufficient to cause such symptoms of cerebral irritation as strabismus, generalized convulsions, inability to walk, contractures, violent temper, involuntary micturition and defecation, and various general muscular movements that cannot be classified. This is precisely the point which has not yet been tested by the operations that have been done. In concluding his remarks, Dr. Gray narrated five cases of craniectomy that have come under his observation.

Dr. C. L. Dana presented a boy, six years old, upon whom Dr. S. D. Powell performed a craniectomy about a year ago. The child was an illegitimate one, and nothing is known of his history up to the first year of his age. $\mathrm{He}$ was rachitic, the fontanelles were large and closed during the third year. During the first three years of his life, the boy suffered with general convulsions, three or four such attacks occurring daily. Up to the time of the operation he was unable to swallow excepting when in the semi-recumbent position, and he could only take liquid food. He could not say a word nor express a thought. Measurements of the head showed it to be below the normal size. A few weeks after the operation he began to talk and could masticate and swallow solid 
food. There has been a very decided and striking increase in the child's intelligence; this became noticeable a few weeks after the operation. Measurements of the skull since the operation have not been particularly instructive. The great circumference of the head has increased only one-half centimetre; the naso-occipital circumference has increased nearly two centimetres. From this it will be observed that the head has grown a little faster than is usual in children of that age.

Dr. Dana also narrated three other cases of craniectomy coming under his observation. All three of these patients died from shock soon after the operation. In conclusion, he stated that he does not see how we can draw any conclusions, one way or the other, as regards the determination of what class of cases should be operated upon. Cases of infantile hemiplegia, with epilepsy and idiocy can hardly ever be benefited by the operation.

Dr. S. D. Powell gave the details of his operation, in the first case narrated by Dr. Dana. A longitudinal incision $5 \frac{1}{2}$ inches long was made, and extending from this two cross-sections of bone were removed, each two inches long. The longitudinal incision was one-fourth of an inch wide. The child made an uneventful recovery, and by the fifth day perfect union was obtained. The dura was not opened. It appeared to be much thickened and there seemed to be a collection of fluid underneath it.

Dr. B. SACHS gave the histories of three cases of craniectomy coming under his observation. In the first two cases, death rapidly. resulted from shock. In the third case a longitudinal section of bone was removed from one side of the skull and the child recovered. Some months afterwards a second operation was undertaken for the purpose of removing a like section of bone on the opposite side of the head. This operation proved fatal. Dr. Sachs presented the skull of this patient. It showed that the longitudinal opening made at the first operation had become firmly closed by the dura (which had not been opened) and by a dense fibrous mass. This occurred during the two months intervening between the first operation and the time of the child's death. This specimen clearly showed, Dr. Sachs said, that the removal of a long strip of bone, as suggested by Lannalongue, is not effective and does not relieve the general pressurc, as he said it would. Our results would no doubt be better if we took out a large flap of bone in the frontal region 
thus giving that portion of the brain which needs it most a chance to develop. In a considerable number of cases of idiocy, it is the frontal portion of the brain that is deficient. The proper cases for operation, he thought, are those in which there are all the symptoms of idiocy, without any symptoms of organic disease of the brain, excepting that of retarded development.

Dr. G. M. HAmmond said that five cases of idiocy for which craniectomy was performed have come under his observation. His own experience, as well as the experience of others with Lannalongue's operation has led to the conclusion that it only stops idiocy. by stopping the life of the child. Of the five patients he has had operated on, two died from shock. In the other three cases-each operated on by a different surgeon - there was a very slight improvement in the intelligence of the children. Not a single case has thus far been reported in which the idiocy was cured. The patients are merely transferred from one degree of idiocy to another. In his opinion, the proper cases to select for operation are those where the patients are only slightly idiotic-not the hopeless cases-and it is well to operate early, before degenerative changes have occurred. The operation should not be undertaker after the sixth or seventh year.

Dr. STARR, in reply to a question, said that craniectomy has apparently been undertaken without regard to age. Keen operated on a patient aged I9 years; Hammond, Sr., operated on one aged 22 years, and Weir operated on one aged $\mathrm{I} 8$.

Dr. NEwTON gave a short review of the literature on this subject. The idea of operating in these cases probably originated in the suggestion made by Virchow, in 1851 , when he attributed cretinism to the premature closure of the cranial sutures. Later on, however (I875), he modified his statements.

Dr. E. C. SEguin said that for a long time he has held the opinion that the early closure of the fontanelles and the premature ossification of the cranium were secondary to the arrest of development of the brain, and he has always advised against operative interference in these cases. Now he stands ready to be convinced as to the value of craniectomy for the relief of such patients. The cases thus far reported, he thought, were not very hopeful. The improvement noted in a few cases has been slight while the surgical results are far from encouraging. 
Dr. Mary Putnam-Jacobi said that according to her recollection of Virchow's monograph, his observations regarding the early closure of the sutures in cretinism only referred to those sutures at the base of the skullthe union of the basilar process with the sphenoid bone.

Dr. SACHS said he regards the operation of craniectomy as an extremely dangerous one, much more so than operations for epilepsy, tumor, etc. The patients are usually very young, and the shock and hæmorrhage are severe.

The PRESIDENT said he thought the members took too pessimistic a view of the operation. He has had six patients operated on without a single death. The total number of cases reported by the speakers, he said, was 23 ; of these, 7 proved fatal. Aside from these, he has collected 37 cases with I 4 deaths, a mortality of about $33 \%$. This rate of mortality he thought was not so very high when we bear in mind that the operation is undertaken to relieve an apparently hopeless condition.

Of the six cases that have come under his observation, three have materially improved in intelligence; the other three were operated on too recently to warrant any definite report at present. The operations were performed by Dr. McBurney. Lannalongue's operation was found to be inefficient, as the area of bone removed soon becomes filled up with a dense fibrous tissue. Wagner's operation was adopted. With the grooved chisel a curved Omega-shaped incision is made through the skull on one side. This flap of bone is then firmly grasped and raised upwards, until it becomes fractured, thus giving plenty of room to the brain underneath. The flap of bone is permanently fixed in its raised position. In one case, both sides of the skull were treated in this way. The chisel, when properly used, causes very little shock. By means of it, the work goes on much faster than with the trephine. The chisel must be very sharp, such as is used for cutting ivory. In conclusion, Dr. Starr said that his experience in these cerebral cases has led him to believe that we know as yet very little about the various pathological conditions of the brain.

The discussion was then closed by Dr. Gray.

The following officers were re-elected for the ensuing year:

For President: Dr. M. Allen Starr.

For ist. Vice-President: Dr. B. Sachs.

For Secretary: Dr. E. D. Fisher. 